\title{
Impact of Cell-phone on Human Health: A Systematic Review of Literatures
}

\author{
Md. Nurul Amin, ${ }^{1}$ Md. Sultan-Ul-Islam, ${ }^{2}$ Md. Jawadul Haque ${ }^{3}$
}

\begin{abstract}
The growth of communication technology in the last two decades has given the world a new look. With the blessings of digital technology, we can now communicate to any parts of the world with just a touch over the screen of our smart phone. Mobile phone hasnow become an indispensable part of our life. But, biological effects of radio-frequency electromagnetic fields (EMF) transmitted by mobile phones are still a matter of public and scientific debate. Countries accross the world are now getting concerned about the impact of mobiles on human health and environment.Radiofrequency waves generated from mobile phones cause potential public health problems. Short-term effects like changes in sleep, heart rate, and blood pressure, and long-term effects like carcinoma (particularly glioma) are well-documented. International Agency for Research on Cancer (IARC) published cancer risks from Radiofrequency(RF) radiation. Human epidemiological studies gave evidence of increased risk for glioma and acoustic neuroma. Further epidemiological, animal and mechanistic studies have strengthened the association. Besides, the carcinogenic effect of non-ionizing radiation emitted from cordless digital devices, numerous health effects have already been claimed to occur. Faced with this context, scientific community and legislative bodies are raising voice for the reduction of RF-EMF exposure to the safe limit for human health and environment. The RF exposure restriction guideline used by many agencies was established in 1998 by the International Commission on Non-Ionizing Radiation Protection (ICNIRP) and was based only on established short-term thermal (heating) effects from RF radiation neglecting non-thermal biological effects. The present study is, therefore, intended to review the literatures relating mobile phone and Wi-fito human health in order to make the scientific community updated on the association between mobile phone use and human health.
\end{abstract}

\section{INTRODUCTION:}

Last two decades have witnessed tremendous growth in communication technology. With the advent of digital technology, we can now communicate to any parts of the world within a moment. The global mobile phone users were 4.57 billions in 2018, which is expected to reach 4.78 billions in 2020 (https://www. statista.com/statistics/274774/forecast-of-mobilephone-users-worldwide/). The number of active smartphones across the globe reached 3.3 billion by the end of 2018 (worldwide, about 39 percent of the population). When looking at smartphone owners by age, penetration is highest among aged $18-24$ years ( $98 \%$ of whom own smartphones) followed by aged
25-34 years (with a $97 \%$ ownership rate), and aged 35-44 years (with a 96\% ownership rate), making smartphones nearly ubiquitous among these generational segments (https://www. google.com/ search?source). The total number of Mobile Phone subscribers in Bangladesh has reached 154.18 million at the end of August, 2018 (http://www.btrc.gov. bd/content/mobile-phone-subscribers-bangladeshaugust-2018) ranking Bangladesh in 9thposition in the world by number of mobile phones in use $(157,048,000)$. The number of internet users in Bangladesh has crossed the 90.5 million mark, and more than 84.6 million access the worldwide web on mobile phone. According to the study, 94.1 percent households in urban areas and 85.2 percent in rural

\section{Authors' information:}

'Dr. Md. Nurul Amin, Assistant Professor, Department of Community Medicine, Rajshahi Medical College, Rajshahi \& Executive Editor, Ibrahim Cardiac Medical Journal, Ibrahim Cardiac Hospital \& Research Institute, Shahbag, Dhaka.

${ }^{2}$ Dr. Md. Sultan-UI-Islam, Professor \& Chairman, Department of Geology Mining, Ex-Director, Institute of Environmental Science, University of Rajshahi, Rajshahi-6205

${ }^{3}$ Dr. Md. Jawadul Haque, Professor \& Head, Department Community Medicine, Rajshahi Medical College, Rajshahi

Correspondence: Dr.Md. Nurul Amin, Mobile:01753178452, E-mail:mdamin01@yahoo.com 
areas are connected with mobile network. And one in every four women in rural areas is connected with mobile network. Keeping pace with the communication technology, the world's economy is growing faster. Thus, mobile phones have become indispensable as communication tools; however, to date, there is an inadequate knowledge on what biological systems could be affected by the use of these devices. Biological effects of radio-frequency electromagnetic fields (EMF) transmitted by mobile phones are still a matter of public and scientific discussion. Sensations of burning or warmth around the ear, ${ }^{1}$ headache ${ }^{2}$, disturbance of sleep ${ }^{3}$, alteration of cognitive functions and neural activity ${ }^{4,5}$, as well as alteration of the blood-brain barrier and a relative decrease in regional cerebral blood flow have been reported as effects resulting from mobile phone use. ${ }^{6,7}$ The potential tumorous effect of EMFs is still a subject of debates \& research. ${ }^{8-11}$ International Agency for Research on Cancer (IARC) published cancer risks from Radiofrequency (RF) radiation. Human epidemiological studies gave evidence of increased risk for glioma and acoustic neuroma. RF radiation was classified as Group 2B, a possible human carcinogen. Further epidemiological, animal and mechanistic studies have strengthened the association. Besides, the carcinogenic effect of non-ionizing radiation emitted from cordless digital devices, numerous health effects have already been claimed to occur. Animal model study showed that long-term exposure of $2.4 \mathrm{GHz}$ RF emitted from Wi-Fi $(2420 \mu \mathrm{W} / \mathrm{kg}, 1 \mathrm{~g}$ average) affects some of the reproductive parameters of male rats (head defects of sperms and weight of the epididymis) suggesting that Wi-Fi users should avoid long-term exposure of RF emissions from Wi-Fi equipment. ${ }^{12}$

Individuals sensitive to electromagnetic fields often experience cognitive impairments which they believe are due to exposure to RF. Furthermore, they complaint of headache and perceive that such symptom is caused by the RF EMF exposure. ${ }^{13}$ Headache is an important warning sign that body temperature is rising to a risky level suggesting that when RF heats body tissues, body temperature and other vital physiological parameters such as heart rate and blood pressure may change. ${ }^{14}$ In spite of this, most countries have taken little or no measure to reduce exposure and educate people on health hazards from RF radiation. On the contrary ambient levels have increased ${ }^{15-17}$ causing concern about its impact on human health. With the increasing use of third generation (3G) mobile phones, social concerns have arisen concerning the possible health effects of radio frequency-electromagnetic fields (RF-EMFs) emitted by mobile phones in humans. ${ }^{18}$ With new technology, increasing environmental exposure levels are found as in measurements of ambient RF radiation at Stockholm Central Station and Stockholm Old Town in Sweden. ${ }^{17,19}$

The exposure guideline used by many agencies was established in 1998 by the International Commission on Non-Ionizing Radiation Protection (ICNIRP) and was based only on established short-term thermal (heating) effects from RF radiation neglecting non-thermal biological effects. The heating effects arise when radiation is so high that it warms up the body by $1^{\circ} \mathrm{C}$ or more after $30 \mathrm{~min}$ exposure at $4 \mathrm{~W} / \mathrm{kg}$ specific absorption rate. ${ }^{20}$ That purpose the present review was aimed at studying the impact of cell phone on human health with particular emphasis to attaining the following objectives.

\section{OBJECTIVES:}

- $\quad$ Find the impact of cell phone (duration of mobile use or talk-time)on physical health in terms of changes in haemodynamic state like local temperature, blood pressure, pulse heart rate etc.

- $\quad$ Study the relationship between mobile phone use \& stress, sleep disturbances, symptoms of depression among young adults.

- Analyze whether increased incidences of certain brain tumours (like glioma \& aucustic neuroma) and thyroid malignancy have link with radiofrequency radiation, emitted from cell-phones and their base-station.

- $\quad$ Find whether the incidence of hearing impairment is increasing with decrease in age incidence of the disease and whether it has any link with mobile use.

- Determine the impact RF emitted from cell-phone and Wi-Fi on fertility of the animal. 
- $\quad$ Determine the level of radiofrequency emitted from mobile phones and whether the exposure level is too far that recommended by ICNIRP

- Put forward some recommendations to help concerned authorities or legislative bodiesso as to shed some light on safety of mobile technology and to constantly monitor the RF radiation exposure from the mobile phone, Wi-fi and other digital devices and their base-stations to keep people safe from their harmful effect.

\section{METHODS:}

This comprehensive review was made based on the literatures of recent and recent past origin. A systematic search of relevant literatures from MEDLINE, PubMed, PMC, Google Scholar and the Cochrane Systematic Review Database was done to identify experimental, cohort, case-control, quasiexperimental, cross-sectional studies relating mobile phone, Wi-fi device and the RF emitted from them with human health. Animal model experimental studies found available on Net werealso included. The collected literatures were critically reviewed about their strengths and weaknesses considering following points systematically.

1. Design: Whether the study was an experimental, longitudinal or cross-sectional one? Randomized controlled trial was ranked highest followed by, cohort, case-control and cross-sectional studies.

2. Type of study population, sample size and sampling procedure: Whether the study population was rightly selected for the design contemplated? Whether the size of the sample and sampling procedure was statistically valid to measure what it intended to measure?

3. Exposure \& outcome (disease) definitions: Whether the exposure and outcome (disease) was defined/operationalised before the start of study? Whether the diagnosis was validated by the latest available diagnostic techniques?

4. Power of the study: What was the power of the study? If the power of the study was below $80 \%$, it was considered as a weaker study to generalize the findings of the study to the reference population.
5. Test statistics used to analyse the data: Whether appropriate test statistics were employed to analyse the data depending upon the type of data and nature of distribution.

6. Causal association: Based on the above criteria if an association was observed between the exposure/factor and outcome, causal association was evaluated by modified Hill's Criteria as follows.

6.1 Strength of association: In general, the stronger the association, the lower the likelihood that the results are attributable to chance.

6.2 Consistency of association: If similar results are found in different studies conducted in different populations, it provides strong evidence for or against causal inference.

6.3 Specificity of association: Finding a single event associated with the factor in question provides more suggestive evidence of a causal association than if multiple unrelated events are found.

6.4 Temporal association: A causal association is more strongly suggested if the events of interest are clustered in time after the exposure than if the events are distributed over a longer and more varied time interval.

6.5 Biologic gradient: The presence of a dose-response effect of drug or toxin or radiation provides increased evidence of causal association.

6.6 Biological plausibility: If the event of interest is consistent with known effects of the factor in question, the evidence of causal association is strengthened.

6.7 Coherence: The evidence should fit together into a reasonable explanation for the observed association between the exposure and the event of interest.

6.8 Experimental evidence: Intervention studies that test a hypothesis can provide evidence for or against causal inference.

In general, the evidence related to benefit or harm of specific interventions is derived from multiple 
sources. These include: epidemiological observational studies which identify associations; clinical research and large-scale randomized clinical trials to establish efficacy, net benefit and cost-effectiveness; randomized clinical trials to establish safety and outcomes research and long-term surveillance data to allow an estimate of outcomes and effectiveness in clinical practice.

\section{LITERATURES REVIEWED:}

\section{Radiofrequency emissions \& physical symptoms:}

Because of the quick development and widespread use of mobile phones, and their vast effect on communication and interactions in work and private life, it is important to study possible negative health effects of the exposure to electromagnetic fields (EMF). The number of people with self-reported electromagnetic hypersensitivity (EHS), who complain of various subjective symptoms such as headache, dizziness and fatigue, has increased during the last couple of decades. However, the origins of EHS remain unclear. Cross-sectional survey studies in different countries have reported that EHS subjects experience non-specific subjective symptoms (e.g., headache, dizziness, fatigue, sleep disorder) associated with EMF exposure: $1.5 \%$ in Sweden, ${ }^{21}$ $3.2 \%$ in California ${ }^{22}$ and $5 \%$ in Switzerland. ${ }^{23}$ For some individuals, the symptoms can have lifestyle-changing consequences. ${ }^{24}$ Self-reported symptoms associated with using of mobile phones most commonly include headaches, earache, \& warmth sensations, ${ }^{25,26}$ and sometimes also perceived concentration difficulties \& fatigue. $^{25}$ However, EMF exposure due to mobile phone use is not currently known to have any major health effects. ${ }^{27}$ Musculoskeletal symptoms due to intensive texting on a mobile phone have also been reported ${ }^{28}$ and techniques used for text entering have been studied in connection with developing musculoskeletal symptoms. ${ }^{29}$

Schoeni and colleagues ${ }^{30}$ conducted a prospective cohort study to see whether memory performance in adolescents is affected by radiofrequency electromagnetic fields (RF-EMF) from wireless device use or by the wireless device use itself due to non-radiation related factors in that context. Verbal and figural memory tasks at baseline and after one year were completed using a standardized, computerized cognitive test battery. Use of wireless devices was inquired by questionnaire and operator-recorded mobile phone use data was obtained for a subgroup of 234 adolescents. RF-EMF dose measures considering various factors affecting RF-EMF exposure were computed for the brain and the whole body. Data were analyzed using a longitudinal approach, to investigate whether cumulative exposure over one year was related to changes in memory performance. All analyses were adjusted for relevant confounders. The study concluded that a change in memory performance over one year is negatively associated with cumulative duration of wireless phone use and more strongly with RF-EMF dose. This may indicate that RF-EMF exposure affects memory performance.

The HERMES (Health Effects Related to Mobile phonE use in adolescents) study conducted on 439 Swiss adolescents (aged 12-17 years) to prospectively investigate whether exposure to radiofrequency electromagnetic fields (RF-EMF) emitted by mobilephones and other wireless communication devices is related to behavioural problems or concentration capacity in adolescents. Behavioural problems were assessed using the Strengths and Difficulties Questionnaire (SDQ), concentration capacity of the adolescents was measured by means of a standardized computerized cognitive test named FAKT. Cross-sectional \& longitudinal (1year of follow-up) analyses were performed to investigate possible associations between behavioural problems and concentration capacity and different exposure measures: self-reported and operator-recorded wireless communication device use, cumulative RF-EMF brain and whole body dose and measured personal RF-EMF exposure. In the cross-sectional analyses behavioural problems were associated with several self-reported wireless device use measures but not operator-recorded mobile phone use measures, concentration capacity was associated with several self-reported and operator- recorded exposures. The longitudinal analyses point towards absence of associations. The lack of consistent exposure-response patterns in the longitudinal analyses suggests that behavioural problems \& 
concentration capacity are not affected by the use of wireless communication devices or RF-EMF exposure. Information bias and reverse causality are likely explanations for the observed cross-sectional findings. ${ }^{31}$

\section{Radiofrequency emissions and cancer risk:}

There has been a growing concern about the possible carcinogenic effects of the electromagnetic radiofrequency fields emitted from mobile phones. Evidences from the INTERPHONE study, a multicenter case-control study and the largest investigation so far of mobile phone use and brain tumors including glioma, acoustic neuroma, and meningiomas, \& other similar studies have proved to be inconclusive in this regard. ${ }^{32}$ However, epidemiological studies provided supportive evidence of increased risk for head and brain tumours, i.e., acoustic neuroma and glioma. RF radiation from devices that emit non-ionizing $\mathrm{RF}$ radiation in the frequency range $30 \mathrm{kHz}-300 \mathrm{GHz}$, is a Group 2B, i.e. a 'possible', human carcinogen. ${ }^{33,34}$ Later studies have corroborated these findings and have thus strengthened the evidence. ${ }^{35,36}$ For children this risk may be accentuated because of a cumulative effect during a long lifetime use. Developing and immature cells can also be more sensitive to exposure to RF radiation. ${ }^{37}$ An animal model study report was released from NTP under the National Institute of Health (NIH) in USA (the largest ever animal study on cell phone RF radiation and cancer). ${ }^{38}$ An increased incidence of glioma in the brain and malignant schwannoma in the heart was found in rats. Acoustic neuroma or vestibular schwannoma is a similar type of tumour as the one found in the heart, although benign. This animal study supported human epidemiological findings on RF radiation and brain tumour risk. ${ }^{36}$ Lack of data of human exposure and mobile use over time periods longer than 15 years warrants further research to explore the linkage of cancer risk \& its use beyond 15 years from the first exposure, especially among younger people, i.e., children and adolescents, who have a potentially longer lifetime of exposure. ${ }^{39,40}$

\section{Radiofrequency emissions and fertility:}

An animal model study was carried out to investigate long-term effects of radiofrequency radiation (RFR) emitted from a Wireless Fidelity (Wi-Fi) system on testes. ${ }^{41}$ The study was carried out on 16 Wistar Albino adult male rats by dividing them into two groups such as control $(n=8)$ and exposure $(n=8)$. Rats in the exposure group were exposed to $2.4 \mathrm{GHz}$ RFR radiation for $24 \mathrm{~h} / \mathrm{d}$ during 12 months (1 year). The same procedure was applied to the rats in the control group except the Wi-Fi system was turned off. The study demonstrated increased abnormal morphology (head defects) of the sperms in the exposure group compared to the control group $(p<0.05)$ while weight of the epididymis and seminal vesicles, seminiferous tubules diameter and tunica albuginea thickness were decreased in the exposure group $(p<0.01, p<0.001, p<0.0001)$.

\section{Radiofrequency emissions and mental and behavioral problems:}

Mental health problems have been increasing among young people around the world. ${ }^{42}$ Cultural and social changes in terms of increased materialism and individualism have been discussed in relation to this, ${ }^{43,44}$ including the possibility of a decreasing stigma about mental illness, improved screening for mental illness, and increased help-seeking behaviors. ${ }^{45}$ Although numerous studies have examined the effects of Global System for Mobile Communications (GSM) on humans between EHS (electromagnetic hypersensitivity) and non-EHS groups, only a few provocation studies involving wideband code division multiple access (WCDMA) have simultaneously evaluated physiological changes, subjective symptoms, and EMF perception. Furubayashi et $\mathrm{al}^{46}$ measured psychological and cognitive parameters during pre- and post-exposure. They also monitored physiological parameters, such as skin temperature, heart rate and local blood flow, and asked participants (EHS and non-EHS women) to report on their subjective perception of EMF emitted by WCDMA devices. They concluded that EHS and non-EHS groups did not differ in their responses to real or control EMF exposure with respect to any psychological, cognitive, or autonomic parameters. Mobile phone addiction is comparable to compulsive gambling and video gaming, having both physical and psychological withdrawal symptoms when they stop using it, like anxiety, restlessness, nervousness, and 
irritability, which disappear when they start using the phone again. The neurophysiological basis for this addiction cannot be ruled out as the role of electromagnetic radiation on the neurotransmitters and the postsynaptic receptors is yet to be explored. ${ }^{47}$

Exposure to radio-frequency \& haemodynamic effect:

Malek and associates ${ }^{48}$ in an experimental study on 200 subjects demonstrated that there is no significant effect of short-term GSM (Global System for Mobile Communication) and UMTS (Universal Mobile Telecommunications System) on body temperature and blood pressure indicating that body temperature and blood pressure are not affected by short term GSM and UMTS. On the other hand, for the heart rate, there is a statistically significant difference between the pre- and post-exposure sessions, $(p<0.05)$. The heart rate of subjects clearly decreases over the course of the exposure, on average, about 3 beats per minute.

Since cellphones emit radiofrequency electromagnetic fields (EMFs), Umar and associates ${ }^{49}$ tested the hypothesis that cellphones placed near the heart might interfere with the electrical rhythm of the heart or affect the blood pressure. Following informed consent, 18 randomly selected apparently healthy male volunteers (mean age $21.44 \pm 0.53$ years) had their blood pressure, pulse rates and ECG measured before and after acute exposure to a cell phone. The ECG parameters obtained were: heart rate (HR), QRS complex duration (QRS), PR interval (PR) and Corrected QT interval (QTC). The blood pressure and pulse rates before and after exposure to the cell phone showed no significant difference. The ECG parameters (HR, QRS duration, PR interval and QTC respectively) did not differ before, during and after calls compared to baseline suggesting that acute exposure to EMFs from cellphones placed near the heart may not interfere with the electrical activity of the heart or blood pressure in healthy individuals; however as the sample size was too small, caution should be exercised to generalize the findings to reference population. It is still believed that the existence of RF-EMF exposure effects from the mobile phones, Wi-fi and their base stations have not been rigorously tested to show their adverse consequences with scientific certainty.

\section{Mobile phone use and hearing impairment:}

There is only a limited knowledge about interaction between electromagnetic fields (EMF) emitted by mobile phones and auditory function. The hearing system is in the closest proximity to the device so that hearing is potentially the most affected target of thermal and non-thermal effects. Moreover, the hearing system and particularly the cochlear outer hair cells $(\mathrm{OHC})$ are known to be highly sensitive to a great variety of exogenous and endogenous agents and externally applied electric and magnetic fields are known to be able to produce some hearing sensation. ${ }^{50}$ Despite all these considerations and evidences, only recently, some studies have analyzed the effects of mobile phones on the auditory system. ${ }^{51,52}$ However, the results are not completely consistent.

The animal experiments using distortion product otoacoustic emissions (DPOAEs) did not show statistically significant changes on the $\mathrm{OHC}$ functionality of adult and developing rats exposed as long as 30 days $1-2 \mathrm{~h}$ per day to EMF at $900 \mathrm{MHz}$ and $1800 \mathrm{MHz}$ frequencies. ${ }^{53,54}$ No measurable change in evoked otoacoustic emissions (OAEs) was detected and none of the subjects reported a deterioration in hearing threshold level after 10-min exposure to the EMFs emitted by mobile phones in a recent human study on possible effects of the EMF of mobile telephones on hearing. ${ }^{55}$ Other studies based on the auditory brainstem response and middle latency response methods concluded that 30 min mobile phone use has no short-term adverse effects on the human auditory system. ${ }^{56,57}$ The small amount of publications shows that there is a big gap in the knowledge of potential biological effects of cellular phone use on hearing.

\section{Impact of mobile phone on children:}

Due to the closer proximity of the mobile phone to the brain of children compared to adults, the average RF exposure from its use is higher by a factor of 2 in a child's brain and by a factor of 10 in the bone marrow of the skull. Brain and bone marrow have a higher conductivity in children than in adults and receive a higher energy deposition from RF sources. With age, the bone marrow progressively incorporates more fat, 
and the bone itself increases in thickness, hardens, and loses water over time, thus making the tissues less vulnerable. ${ }^{34}$ Adolescents belong to the heaviest users of wireless communication devices, but little is known about their personal exposure to radiofrequency electromagnetic fields (RF-EMF). A study was conducted to describe personal RF-EMF exposure of Swiss adolescents and evaluate exposure relevant factors. Furthermore, personal measurements were used to estimate average contributions of various sources to the total absorbed RF-EMF dose of the brain and the whole body. A total of 90 adolescents (aged 13 to 17 years) participated in the study conducted over a period of one year. Personal exposure was measured using a portable RF-EMF measurement device (ExpoM-RF) measuring 13 frequency bands ranging from 470 to $3600 \mathrm{MHz}$. The participants carried the device for three consecutive days and kept a time-activity diary. In addition, personal measurement values were combined with dose calculations for the use of wireless communication devices to quantify the contribution of various RF-EMF sources to the daily RF-EMF dose of adolescents. The result obtained showed that RF-EMF exposure of adolescents is dominated by their own mobile phone use (67.2\%). Environmental sources such as mobile phone base stations play a minor role $(19.8 \%)$. WLAN at school and at home had little impact on the personal measurements (WLAN accounted for $3.5 \%$ of total personal measurements). According to the dose calculations, exposure from environmental sources (broadcast transmitters, mobile phone base stations, cordless phone base stations, WLAN access points, and mobile phones in the surroundings) contributed on average $6.0 \%$ to the brain dose and $9.0 \%$ to the whole-body dose. ${ }^{58}$ Although WHO has concluded that current scientific evidence does not justify specific measures for children, nevertheless, steps to reduce RF exposure, i.e., reduce the amount of time spent on the mobile phone and use speaker mode or a headset to place it at a distance from the head, can be applied to children and teenagers as well. 59

\section{Other effects:}

The use of mobile phones by students at places and situations where its use should be restricted is quite common, as studied by Subba et al., which ranged from $17.9 \%$ usage while driving to $95.5 \%$ while in classrooms. ${ }^{60}$ Mahmoodabad et al. ${ }^{61}$ reported $84 \%$ usage among medical students in classrooms and $18.6 \%$ during driving."Ringxiety" (phantom ringing) resulting in hampering of studies was experienced by $34.5 \%$ of the students who mostly used their phones at classrooms (99\%) and libraries (60.3\%). ${ }^{60}$

\section{DISCUSSION:}

Mobile phone has become a part and parcel of our life. We cannot do even a single day without a mobile. But how much we are aware what deleterious effect it produces on our health and environment. Despite being the best instrument, for better communication, there has always been counter arguments \& research over the increasing use of mobile phones and its short-term and long-term health effects. Mobile phones are low-powered radiofrequency (RF) transmitters, with frequencies between 450 and 2700 $\mathrm{MHz}$, operating through a network of base stations, with power in the range of 0.1-2 $\mathrm{W}$ transmitted through an antenna used close to the user's head. ${ }^{39}$ It uses RF fields in the form of electromagnetic waves which are transmitted from the handset to the closest base station to connect calls, text messages, emails, pictures, and web downloads to the main telephone network. 62 Thus, human exposure to RF radiation can occur from a variety of sources, including the use of personal devices (mobile phones, cordless phones, Wi-Fi, Bluetooth etc.), occupational \& environmental sources (broadcast antennas, high- power pulsed radars etc. ). ${ }^{34}$ The RF part of the electromagnetic field (EMF) is that part of the spectrum with frequencies in the range of $3 \mathrm{kHz}$ to $300 \mathrm{GHz}$ which is not sufficient enough to cause molecular level ionization \& hence is a type of "non-ionizing radiation". It only results in tissue heating with a negligible rise in body temperature, often referred to as "thermal" effects. ${ }^{63}$ However, the carcinogenic potential of EMF, changes in the permeability of the blood-brain barrier, electroencephalographic activity, and changes in blood pressure have been reported. ${ }^{64}$ Short-term effects like changes in sleep, heart rate, and blood pressure headache, earache, \& warmth sensation, concentration difficulties, and fatigue have been highlighted by numerous studies, ${ }^{65}$ while long-term 
effects like carcinomaare well-documented. ${ }^{36,36}$ Hence, given the immense number of mobile phone users, even a small increase in the incidence of adverse effects on health can have major public health implications. To know how health hazards could be caused from RF exposure, it is essential to know the mechanism of action of RF in biological tissue.

\section{Mechanism of action of RF in biological tissue:}

Tissue heating is the principal mechanism of interaction between RF energy and the human body. At the frequencies used by mobile phones, most of the energy is absorbed by the skin and other superficial tissues, resulting in negligible temperature rise in the brain or in any other organs of the body and, thus, they do not pose any proven health hazards. However, much of public health concern revolves around the possibility of hazards from long-term exposure to levels which do not produce measurable heating. ${ }^{59}$ Effects on brain electrical activity, cognitive function, sleep, heart rate, and blood pressure in volunteers have also been investigated, as well as for self-reported symptoms, but consistent evidence of adverse effects from exposure to RF field at levels below which those causing tissue heating is lacking. ${ }^{40,64}$

In the meantime, the World Health Organization (WHO) and government agencies like Federal Communications Commission (FCC) of the United States have laid down specific limits for human exposure to RF emissions from hand-held mobile phones in terms of specific absorption rate (SAR), a measure of the rate of absorption of RF energy by the body. ${ }^{62,63}$ The FCC's exposure guidelines demarcate an SAR of $1.6 \mathrm{~W} / \mathrm{kg}$, averaged over $1 \mathrm{~g}$ of tissue, as the safe limit for a mobile phone user and every handset should comply with this limit before FCC approval is granted for marketing of a phone in the United States. However, less restrictive limits, e.g., 2 W/kg averaged over $10 \mathrm{~g}$ of tissue, are specified by the International Commission on Non-Ionizing Radiation Protection (ICNIRP) guidelines, endorsed by $\mathrm{WHO}$, and used in Europe and most other countries. ${ }^{63} \mathrm{WHO}$ recommends that these standards are protective of all persons; nevertheless, if individuals are concerned about avoiding even potential risks, they can take a few simple steps to minimize their exposure to RF energy. ${ }^{59}$
Exposure of a user to RF falls off rapidly with increasing distance from the handset. A person using a mobile phone $30-40 \mathrm{~cm}$ away from the body, i.e., using speaker mode while talking or using a "hands free" device, e.g., bluetooth headsets, will, therefore, have a much lower exposure than someone holding the handset against the head.64 A mobile phone usually operates on the lowest power necessary to maintain call quality. ${ }^{59}$ Although various devices which claim to increase the safety of mobile phone use, e.g., shielded cases, earpiece pads/shields, antenna clips/caps, special batteries, and absorbing buttons, reduce exposures by a factor of 10 , they have the danger of adversely affecting the phone's antenna, due to which the phone will attempt to transmit more power up to its specified maximum. ${ }^{34,59}$ Till date, scientific evidence does not indicate any need for shields on mobile phones, and therefore, such add-on devices should be judiciously used. ${ }^{59}$ Using the phone in areas of good reception also decreases exposure as it allows the phone to transmit at reduced power. ${ }^{59,64}$ Since time is a key factor in how much exposure a person receives, reducing the time spent on usage by limiting the number and length of calls may reduce RF exposure. ${ }^{59,63}$ Revolutionary changes in mobile phone technology have lowered the RF power emissions from the newer devices like the third-generation (3G) phones where it is two times lowered and Digital Enhanced Cordless Telecommunications (DECT) where the risk is almost five times lowered than the older versions. ${ }^{34}$

When mobile phones are used very close to certain medical devices including pacemakers (within about 8 inches), implantable defibrillators, and certain hearing aids, they may malfunction due to their susceptibility to electromagnetic signals. ${ }^{63}$ The risk is much reduced for $3 G$ phones and newer devices. ${ }^{66}$ Hence, to avoid this potential problem, pacemaker patients can avoid placing a phone in a pocket close to the location of their pacemaker. ${ }^{63}$

\section{Basis for limiting exposure according to ICNIRP:}

The evidences gleaned from the studies discussed so far, claims the reduction of RF-EMF exposure to the safe limit human. The RF exposure restriction guideline used by many agencies was established in 1998 by the International Commission on 
Non-Ionizing Radiation Protection (ICNIRP) and was based only on established short-term thermal (heating) effects from RF radiation neglecting non-thermal biological effects. Induction of cancer from long-term EMF exposure was not considered to be established, and so these guidelines are based on short-term, immediate health effects such as stimulation of peripheral nerves \& muscles, shocks due to elevated tissue temperatures resulting from absorption of energy during exposure to EMF. In the case of potential long-term effects of exposure, such as an increased risk of cancer, ICNIRP concluded that available data are insufficient to provide a basis for setting exposure restrictions, although epidemiological research has provided suggestive evidence of an association between possible carcinogenic effects. ${ }^{67}$

This is an exceptional statement by ICNIRP, and found in many statements of groups following the ICNIRP philosophy like the AGNIR and on the WHO EMF Project's homepage as well, that epidemiology found 'suggestive, but unconvincing' evidence. What is convincing or not is so decidedly subjective that no scientific body will ever make this as a basis for a decision. There might be gaps in knowledge that make it difficult to decide about the mechanisms that underlie an observation \& even an observation could be considered unreliable but the conviction must not enter a rational discourse about a scientific issue.

The guidelines were updated in 2009 but still do not cover cancer and other long-term or non-thermal health effects. ICNIRP gives the guideline 2 to 10 $\mathrm{W} / \mathrm{m}^{2}$ for RF radiation depending on frequency, thus only based on a short-term immediate thermal effect. ${ }^{68}$ ICNIRP is a private organisation (NGO) based in Germany. New expert members can only be elected by members of ICNIRP. Many of ICNIRP members have ties to the industry that is dependent on the ICNIRP guidelines. The guidelines are of huge economic and strategic importance to the military, telecom/IT and power industry.

In contrast to ICNIRP, the BioInitiative Reports from 2007, updated in 2012, based the evaluation also on non-thermal health effects from RF radiation. ${ }^{69}$ The scientific benchmark for possible health risks was defined to be 30 to $60 \mu \mathrm{W} / \mathrm{m}^{2}$. Thus, using the significantly higher guideline by ICNIRP gives a 'green card' to roll out the wireless digital technology thereby not considering non-thermal health effects from RF radiation. Numerous health hazards are disregarded such as cancer, ${ }^{36}$ effects on neurotransmitters and neuroprotection, ${ }^{70,71}$ blood- brain-barrier, ${ }^{72,73}$ cognition, ${ }^{74,75}$ psychological addiction, ${ }^{76}$ sleep, ${ }^{77,78}$ behavioral problems 79,80 and sperm quality. ${ }^{12,81}$

\section{WHO Factsheet (opinion)}

A Fact Sheet from WHO issued in June 2011 shortly after the IARC cancer classification in May 2011 stated that 'To date, no adverse health effects have been established as being caused by mobile phone use'.82 In the WHO Fact Sheet it was also stated that 'WHO will conduct a formal risk assessment of all studied health outcomes from radiofrequency fields exposure by 2012 . Why WHO was so keen to make a new risk evaluation shortly after the IARC evaluation. The statement was not based on scientific evidence at that time on a carcinogenic effect from RF radiation. And it was hardly expected that new studies would be published in short time changing the classification of RF radiation as a possible, Group 2B, human carcinogen. Considering the WHO statement of 'no adverse health effects' the aim might have been to undermine the IARC decision and give the telecom industry a 'clean bill' of health. ${ }^{36}$ It might, however, be argued that as a result of the IARC classification, it was necessary for WHO to also look at other effects, and not just tumours.

\section{CONCLUSION}

From the review it is evident that countries around the world are now beginning to get concerned about the impact of mobiles on human health and environment. Radiofrequency waves generated from mobile phones cause potential public health problems. Short-term effects like changes in sleep, heart rate, and blood pressure, and long-term effects like carcinoma (particularly glioma) are well- documented. So there is need for reviewing the existing safety rules taking into account many new studies on the safety of cellphones and other wireless devices and based the review, new laws to be stringently enforced to constantly monitor the RF emitted from the mobile phones, Wi-fi and other digital devices and their base-stations to keep people safe from their harmful 
effects. This should be supplemented by mass media to raise awareness among people regarding the possible health effects of radiofrequency emissions from mobile phones and the guidelines to minimize its exposure. There should be a high level scientific body as well in every country to undertake studies based on their respective needs and to put forward recommendations to the legislative bodies to help them update the safety rules for mobile phone and other digital devises. It is the need of the hour to teach young people to be customized, to know when to have the cell phone on, and to avoid becoming the slave of technology instead of its mastery.

\section{REFERENCES}

1. Oftedal G, Wilen J, Sandstrom M, Mild KH. Symptoms experienced in connection with mobile phone use. Occup Med (Lond) 2000;50:237-45.

2. Frey AH. Headaches from cellular telephones: are they real and what are the implications? Environ Health Perspect 1998;106:101-03.

3. Borbely AA, Huber R, Graf T, Fuchs B, Gallmann E, Achermann P. Pulled high-frequency electromagnetic field affects human sleep and sleep electroencephalogram. Neurosci Lett 1999;275:207-10. doi: 10.1016/S03043940(99)00770-3.

4. Preece AW, Iwi G, Davies-Smith A. Effect of a 915-MHz simulated mobile phone signal on cognitive function in man. Int J Radiat Biol 1999;75:447-56. doi: 10.1080/ 095530099140375.

5. Hamblin DL, Wood AW, Croft RJ, Stough C. Examining the effects of electromagnetic fields emitted by GSM mobile phones on human event-related potentials and performance during an auditory task. Clin Neurophysiol 2004; 115:171-78. doi: 10.1016/S1388-2457(03) 00313-4.

6. Fritze K, Sommer C, Schmitz B. Effect of global system for mobile communication (GSM) microwave exposure on blood-brain barrier permeability in rat. Acta Neuropathol (Berl) 1997;94:465-470. doi: 10.1007/s0040 10050734.

7. Haarala $C$, Aalto $S$, Hautzel $H$, Julkunen L, Rinne JO, Laine M, Krause B, Hamalainen $\mathrm{H}$. Effects of a $902 \mathrm{MHz}$ mobile phone on cerebral blood flow in humans: a PET study. Neuroreport 2003;14:2019-23. doi: 10.1097/00001756200311140-00003.

8. Moulder JE, Erdreich LS, Malyapa RS, Merritt J, Pickard WF, Vijayalaxmi Cell phones and cancer: what is the evidence for a connection? Radiat Res 1999;151: 513-31.

9. Blettner M, Berg G. Are mobile phones harmful? Acta Oncol 2000;39:927-30. doi:10.1080/0284186005021 5891.
10. Christensen HC, Schuz J, Kosteljanetz M, Poulsen SH, Thomsen J, Johansen Christoffer J. Cellular telephone use and risk of acoustic neuroma. Am J Epidemiol 2004;159: 277-83. doi: 10.1093/aje/kwh032.

11. Lonn S, Ahlbom A, Hall P, Feychting M. Mobile phone use and the risk of acoustic neuroma. Epidemiology 2004; 15:653-59. doi: 10.1097/01.ede.0000142519. 00772.bf.

12. Dasdag $S$, Taş $M$, Akdag MZ, Yegin K. Effect of long-term exposure of $2.4 \mathrm{GHz}$ radiofrequency radiation emitted from Wi-Fi equipment on testes functions. Electromagn Biol Med 2015;34:37-42. doi: 10.3109/15368378.2013. 869752.

13. Röösli M., Moser M., Baldinini Y., Meier M, Braun-Fahrländer C. Symtpoms of ill health ascribed to electromagnetic field exposure-a questionnaire survey. International Journal of Hygiene Environmental Health 2004;207:141-50.

14. Mc Kinlay AF. Review of the scientific evidence for limiting exposure to electromagnetic fields $(0-300 \mathrm{GHz})$. Docs NRPB 2004;15:83.

15. Abramson MJ, Benke GP, Dimitriadis C, Inyang IO, Sim MR, Wolfe RS, Croft RJ. Mobile telephone use is associated with changes in cognitive function in young adolescents. Bioelectromagnetics 2009;30:678-86. doi: 10.1002/bem. 20534.

16. Spitzer M. Information technology in education: Risks and side effects. Trends Neurosci Educ 2014;3:81-85. doi: 10.1016/j.tine.2014.09.002

17. Hardell L, Carlberg M, Koppel T, Hedendahl L. High radio-frequency radiation at Stockholm Old Town: An exposimeter study including the Royal Castle, Supreme Court, three major squares and the Swedish Parliament. Mol Clin Oncol 2017;6:462-76.

18. Heinrich S, Thomas S, Heumann C, vonKries R, Radon K. Association between exposure to radiofrequency electromagnetic fields assessed by dosimetry and acute symptoms in children and adolescents: a population based cross-sectional study. Environ Health 2010;9:75. doi: 10.1186/1476-069X-9-75.

19. Hardell L, Koppel T, Carlberg M, Ahonen M, Hedendahl L. Radiofrequency radiation at Stockholm Central Railway Station in Sweden and some medical aspects on public exposure to RF fields. Int J Oncol 2016;49:1315-24.

20. What are electromagnetic fields? Viewed 10 march 2019 <http://www.who.int/peh-emf/about/WhatisEMF/en/index4.html). >

21. Hillert L, Berglind N, Arnetz BB, Bellander T. Prevalence of self-reported hypersensitivity to electric or magnetic fields in a population-based questionnaire survey. Scand J Work Environ Health 2002;28:33-41. doi: 10.5271/sjweh.644. 
22. Levallois P, Neutra R, Lee G, Hristova L. Study of self-reported hypersensitivity to electromagnetic fields in California. Environ Health Perspect 2002;110(Suppl 4):619-23.

23. Schröttner J, Leitgeb N, Hillert L. Investigation of electric current perception thresholds of different EHS groups. Bioelectromagnetics 2007;28:208-13. doi: 10.1002/bem. 20294.

24. Mild KH, Repacholi M, Deventer E, Ravazzani P, editor. Proceedings of an International Workshop on EMF Hypersensitivity: 25-27 October 2004. World Health Organization; 2006.

25. Johansson A, Nordin S, Heiden M, Sandström M. Symptoms, personality traits, and stress in people with mobile phone-related symptoms and electromagnetic hypersensitivity. Journal of Psychosomatic Research 2010;68(1): 37-45.doi:10.1016/j.jpsychores.2009. 06.009;

26. Korpinen LH, Pääkkönen RJ. Self-report of physical symptoms associated with using mobile phones and other electrical devices. Bioelectromagnetics 2009;30(6):431 -37. doi: 10.1002/bem.20500.],

27. SSM. SSM Report 2009:36. Swedish Radiation Safety Authority; 2009. Recent Research on EMF and Health Risks. Sixth annual report from SSM:s Independent Expert Group on Electromagnetic Fields.

28. Ming Z, Pietikainen S, Hänninen O. Excessive texting in pathophysiology of first carpometacarpal joint arthritis. Pathophysiology 2006;13(4):269-70. doi: 10.1016/j.pathophys.2006.09.001

29. Gustafsson E, Johnson PW, Hagberg M. Thumb postures and physical loads during mobile phone use - a comparison of young adults with and without musculoskeletal symptoms. Journal of Electromyography and Kinesiology 2010;20(1):127-35. doi: 10.1016/j.jelekin.2008.11.010.].

30. Schoeni A, Roser K, Röösli M. Memory performance, wireless communication and exposure to radiofrequency electromagnetic fields: A prospective cohort study in adolescents. Environ Int 2015;85:343-51. doi:10. 1016/j. envint.2015.09.025.

31. Roser K, Schoeni A, Röösli M. Mobile phone use, behavioural problems and concentration capacity in adolescents: A prospective study. Int J Hyg Environ Health 2016;219(8):759-69. doi: 10.1016/j.ijheh. 2016. 08.007.

32. The INTERPHONE Study. International Agency for Research on Cancer. World Health Organization. Available from: Website to be given here. [Last accessed on 2014 May 10; What are the Health Risks Associated with Mobile Phones and their Base Stations? Available from:Website to be given here. [Last accessed on 2014 May 10].)

33. Baan R, Grosse Y, Lauby-Secretan B, El Ghissassi F, Bouvard V, Benbrahim-Tallaa L, Guha N, Islami F, Galichet
L. Carcinogenicity of radiofrequency electromagnetic fields. Lancet Oncol 2011;12:624-26. doi:10.1016/ S1470-2045(11)70147-4.

34. Herbert MR, Sage C. Autism and EMF? Plausibility of a pathophysiological link - Part I. Pathophysiology 2013; 20:191-209. doi: 10.1016/j.pathophys.2013. 08.001.

35. Hardell L, Carlberg M, Söderqvist F, Hansson Mild K. Case-control study of the association between malignant brain tumours diagnosed between 2007 and 2009 and mobile and cordless phone use. Int $J$ Oncol 2013;43:1833-45.

36. Carlberg M, Hardell L. Evaluation of mobile phone and cordless phone use and glioma risk using the Bradford Hill viewpoints form 1965 on association or causation. Bio Med Res Int 2017;2017:9218486. doi: 10.1155/ 2017/ 9218486 .

37. Markovà E, Malmgren LO, Belyaev IY. Microwaves from mobile phones inhibit 53BP1 focus formation in human stem cells more strongly than in differentiated cells: Possible mechanistic link to cancer risk. Environ Health Perspect 2010;118:394-99.

38. Wyde M, Cesta M, Blystone C, Elmore S, Foster P, Hooth M et al. Report of Partial findings from the National Toxicology Program Carcinogenesis Studies of Cell Phone Radiofrequency Radiation in Hsd: Sprague Dawley ${ }^{\circledR}$ SD rats (Whole Body Exposures) US National Toxicology Program (NTP); 2016. doi: org/10.1101/ 055699.http://biorxiv.org/content/biorxiv/early/2016 /05/26/055699.full.pdf. Accessed on April 1, 2017.

39. Fact Sheet No. 193. Electromagnetic Fields and Public Health: Mobile Phones. Geneva: World Health Organization; 2014. p. 1 ;

40. Röösli M, Frei P, Mohler E, Hug K. Systematic review on the health effects of exposure to radiofrequency electromagnetic fields from mobile phone base stations. 2010;88:887-96F; What are the Health Risks Associated with Mobile Phones and their Base Stations? Available from: Last accessed on 2014 May 10].

41. Dasdag S, Taş M, Akdag MZ, Yegin K. .Effect of long-term exposure of $2.4 \mathrm{GHz}$ radiofrequency radiationemitted from Wi-Fi equipment on testes functions. Electromagn Biol Med 2015;34(1):37-42. doi: 10.3109/ 15368378. 2013. 869752.

42. Patel V, Flisher AJ, Hetrick S, McGorry P. Mental health of young people: a global public-health challenge. Lancet 2007;369(9569):1302-13. doi:10.1016/ S0140-6736 (07)60368-7; Statistics Sweden. LE Living conditions. Stockholm. Sweden; 2006. Health and medical care 1980-2005. 
43. Eckersley R. Is modern Western culture a health hazard? International Journal of Epidemiology 2006; 35(2): 252-58. doi: 10.1093/ije/dyi235.

44. Eckersley R. Commentary on Trzesniewski and Donnellan (2010) Perspectives on Psychological Science. 2010;5 (1):76-80. doi: 10.1177/1745691609357014.

45. Hunt J, Eisenberg D. Mental health problems and help-seeking behavior among college students. Journal of Adolescent Health 2010;46(1):3-10.doi:10.1016/ j.jadohealth.2009.08.008.

46. Furubayashi T, Ushiyama A, Terao Y, Mizuno Y, Shirasawa $\mathrm{K}$, Pongpaibool $\mathrm{P}$ et al. Effects of short-term W-CDMA mobile phone base station exposure on women with or without mobile phone related symptoms. Bioelectromagnetics 2009;30:100-13. doi: 10. 1002/bem.20446.].

47. Puente MP, Balmori A. Addiction to cell phones: Are there neurophysiological mechanisms involved? Proyecto 2007;61:8-12.

48. Malek F, Rani KA, Rahim HA and Omar MH. Effect of Short-Term Mobile Phone Base Station Exposure on Cognitive Performance, Body Temperature, Heart Rate and Blood Pressure of Malaysians. Sci Rep 2015;5:13206. Published online 2015 Aug 19. doi: 10.1038/srep13206 PMCID: PMC4541152.

49. Umar ZU, Abubakar MB, Ige J, Igbokwe UV, Mojiminiyi FB, Isezuo SA. Effect of Mobile Phone Radiofrequency Electromagnetic Fields on. Niger J Physiol Sci 2014;29(2):137-40.

50. Watanabe Y, Tanaka T, Taki M, Watanabe S. FDTD Analysis of Microwave Hearing Effect. IEEE Trans Microwave Theory Tech 2000;48:2126-32. doi: 10.1109/22. 884204.

51. Kellenyi L, Thurockzy G, Faludy B, Lenard L. Effects of mobile GSM radiotelephone exposure on the auditory brainstem response (ABR). Neurobiology 1999;7:79-81.

52. Marino C, Cristalli G, Galloni P, Pasqualetti P, Piscitelli M, Lovisolo GA. Effects of Micro-waves (900 MHz) on the cochlear receptor: exposure systems and preliminary results. Radiat Environment Bioph 2000;39:131-36. doi: $10.1007 /$ s004110000049.

53. Parazzini M, Marino C, Galloni P, Piscitelli M, Tognola G, Grandori F, Ravazzani P. Effects of electromagnetic fields on hearing: study of the influence of GSM cellular phones on the inner auditory system of Sprague-Dawley rats. Proceedings $2^{\text {nd }}$ Medical and Biological Engineering Conference, Vienna. pp. 1290-1. 2002, December 4-8.

54. Kizilay A, Ozturan O, Erdem T, Kalcioglu T, Miman MC. Effects of chronic exposure of electromagnetic fields from mobile phones on hearing in rats. Auris Nasus Larynx 2003;30:239-45. doi: 10.1016/S0385-8146(03)00054-3.
55. Ozturan O, Erdem T, Miman MC, Kalcioglu MT, Oncel S. Effects of the electromagnetic field of mobile telephones on hearing. Acta Otolaryngol 2002;122:289-93. doi: $10.1080 / 000164802753648178$.

56. Arai N, Enomoto $\mathrm{H}$, Okabe $\mathrm{S}$, Yuasa $\mathrm{K}$, Kamimura $\mathrm{Y}$, Ugawa $Y$. Thirty minutes mobile phone use has no short-term adverse effects on central auditory pathways. Clin Neurophysiol 2003;114:1390-94.doi:10.1016/S1388-2457 (03)00124-X.

57. Bak M, Sliwinska-Kowalska M, Zmyslony M, Dudarewicz A. No effect of acute exposure to the electromagnetic field emitted by mobile phones on brainstem auditory potentials in young volunteers. Int J Occup Med Environ Health 2003;16:201-09.

58. Roser K, Schoeni A, Struchen B, Zahner M, Eeftens M, Frohlich J, Roosli M. Personal radiofrequency electromagnetic field exposure measurements in Swiss adolescents. Environ Int 2017;99:303-14. doi: 10.1016/j.envint.2016. 12.008 .

59. Mobile Communications and Health. GSMA Head Office, Level 7, 5 New Street Square, New Fetter Lane, London, EC4A 3BF, United Kingdom. Available from: http://www.gsma.com/health. Last accessed on 2014 May 10; Children and Cell Phones. Radiation Emitting Products. US Food and Drug Administration).

60. Subba SH, Mandelia C, Pathak V, Reddy D, Goel A, Tayal $A$, et al. Ringxiety and the mobile phone usage pattern among the students of a medical college in South India. $J$ Clin Diagn Res 2013;7:205-9.

61. Mahmoodabad SS, Barkhordari A, Nadrian H, Moshiri O, Yavari MT. Survey of ownership and use of mobile phones among medical science students in Yazd. 2009;12: 1430-3.

62. EMF Explained Series. Available from: http://www.emfexplained.info/. Last accessed on 2014 May 10

63. Radiofrequency Safety-Office of Engineering and Technology (OET): Frequently Asked Questions about the Safety of Radiofrequency (RF) and Microwave Emissions from Transmitters and Facilities Regulated by the FCC. Available from: http:. [Last accessed on 2014 May 9

64. Fact Sheet No. 193, WHO, 2014; Braune S, Wrocklage C, Raczek J, Gailus T, CH. Resting blood pressure increase during exposure to a radio-frequency electromagnetic field. Lancet 1998;351:1857-58

65. Korpinen LH, Pääkkönen RJ. Self-report of physical symptoms associated with using mobile phones and other electrical devices. Bioelectromagnetics 2009;30:431-7.

66. Bagla P. Indian Report, at Odds With Mainstream, Raises Mobile Phone Concerns. Available from: [Last accessed on 2014 Jun 28 
67. ICNIRP Guidelines, viewed 10 March $2019<$ http://www.icnirp.org/cm/upload/publications/ICNIRPemfgdl.pdf>

68. International Commission on Non-Ionizing Radiation Protection ICNIRP statement on the 'Guidelines for limiting exposure to time-varying electric, magnetic, and electromagnetic fields (up to $300 \mathrm{GHz}$ )'. Health Phys 2009; 97:257-58. doi: 10.1097/HP.0b013e3181aff9db.).

69. Bio Initiative Working Group BioInitiative Report: A Rationale for a Biologically-based Public Exposure Standard for Electromagnetic Fields (ELF and RF) Sage C, Carpenter DO, editors. Bioinitiative. 2007http://www.bioinitiative.org/table-of-contents/. Accessed on April 1, 2017; BioInitiative Working Group BioInitiative 2012 A Rationale for a Biologically-based Exposure Standard for Electromagnetic Fields (ELF and RF) Sage C, Carpenter DO, editors. Bioinitiative. 2012http://www.bioinitiative.org/table-of-contents/. Accessed on April 1, 2017

70. Buchner K, Eger H. Changes of clinically important neurotransmitters under the influence of modulated RF fields-A long-term study under real-life conditions. Umwelt-Medizin-Gesellschaft 2011;24:44-57. (In German). https://www.avaate.org/IMG/pdf/Rimbach-Study20112.pdf.

71. Fragopoulou AF, Samara A, Antonelou MH, Xanthopoulou $A$, Papadopoulou A, Vougas $K$ et al. Brain proteome response following whole body exposure of mice to mobile phone or wireless DECT base radiation. Electromagn Biol Med 2012;31:250-74. doi: 10.3109/15368378.2011. 631068.

72. Nittby H, Brun A, Eberhardt J, Malmgren L, Persson BR, Salford LG. Increased blood-brain barrier permeability in mammalian brain 7 days after exposure to the radiation from a GSM-900 mobile phone. Pathophysiology 2009; 16:103-12. doi: 10.1016/j.pathophys.2009.01.001.

73. Tang J, Zhang Y, Yang L, Chen Q, Tan L, ZuoS et al. Exposure to $900 \mathrm{MHz}$ electromagnetic fields activates the mkp-1/ERK pathway and causes blood-brain barrier damage \& cognitive impairment in rats. Brain Res 2015; 1601:92-101. doi: 10.1016/j.brainres.2015.01.019.

74. Deshmukh PS, Nasare N, Megha K, Banerjee BD, Ahmed RS, Singh $D$ et al. Cognitive impairment and neurogenotoxic effects in rats exposed to low-intensity microwave radiation. Int J Toxicol 2015;34:284-90. doi: 10.1177/

\section{8.}

75. Calvente I, Pérez-Lobato R, Núñez MI, Ramos R, Guxens M, Villalba J, Olea N, Fernández MF. Does exposure to environmental radiofrequency electromagnetic fields cause cognitive and behavioral effects in 10-year-old boys? Bioelectromagnetics 2016;37:25-36. doi: 10.1002 /bem.21951.

76. Roser K, Schoeni A, Foerster M, Röösli M. Problematic mobile phone use of Swiss adolescents: Is it linked with mental health or behaviour? Int J Public Health 2016;61:307-15. doi: 10.1007/s00038-015-0751-2.

77. Carter B, Rees P, Hale L, Bhattacharjee D, Paradkar MS. Association between portable screen-based media device access or use and sleep outcomes: A systematic review and meta-analysis. JAMA Pediatr 2016;170:1202-08. doi: 10.1001/jamapediatrics.2016.2341.

78. Belyaev I, Dean A, Eger H, Hubmann G, Jandrisovits R, Kern $M$ et al. EUROPAEM EMF Guideline 2016 for the prevention, diagnosis and treatment of EMF-related health problems and illnesses. Rev Environ Health 2016;31: 363-97. doi: 10.1515/reveh-2016-0011.

79. Herbert MR, Sage C. Autism and EMF? Plausibility of a pathophysiological link part II. Pathophysiology 2013;20: 211-34. doi: 10.1016/j.pathophys.2013.08.002.

80. Sudan M, Olsen J, Arah OA, Obel C, Kheifets L. Prospective cohort analysis of cellphone use and emotional and behavioural difficulties in children. J Epidemiol Community Health 2016; doi: 10.1136/jech-2016-207419. Epub ahead of print.

81. Avendaño C, Mata A, Sanchez Sarmiento CA, Doncel GF. Use of laptop computers connected to internet through Wi-Fi decreases human sperm motility \& increases sperm DNA fragmentation. Fertil Steril 2012;97:39-45.e2. doi: 10.1016/j.fertnstert.2011.10.012.

82. WHO, Electromagnetic fields and public health: mobile phones, viewed 10 March 2019 <http://www.who.int/mediacentre/fact-sheets/fs193/en/> 